DOI:

10.1038/nri2143

\title{
Reciprocal regulation by retinoic acid
}

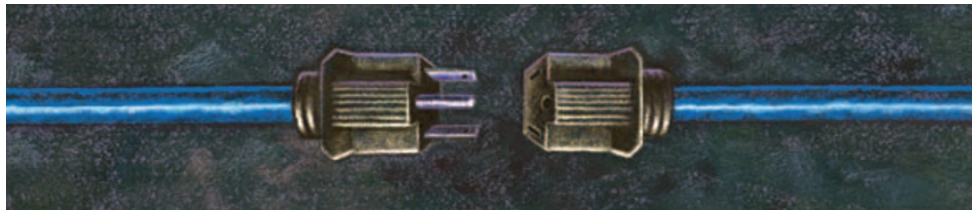

How can transforming growth factor- $\beta$ (TGF $\beta$ ) induce the differentiation of both regulatory $\mathrm{T}$ cells and $\mathrm{T}$ helper $17\left(\mathrm{~T}_{\mathrm{H}} 17\right)$ cells - two T-cell subsets that have opposing functions? Recent studies have indicated that the presence of additional pro-inflammatory cytokines, such as interleukin-6 (IL-6), is necessary for $T_{H} 17$-cell differentiation. Now Mucida et al. show that the vitamin A metabolite retinoic acid is a key regulator of TGF $\beta$-induced T-cell differentiation.

The authors compared the ability of mucosal and splenic dendritic cells (DCs) to promote the differentiation of $\mathrm{T}_{\mathrm{H}} 17$ cells and found that, in the presence of TGF $\beta$ and IL-6, mesenteric lymph node (MLN) DCs were less effective than splenic DCs at inducing $\mathrm{T}_{\mathrm{H}} 17$-cell differentiation. Because previous studies have functionally linked retinoic acid and mucosal DCs, the authors determined whether there was a role for retinoic acid in the reduced capacity of MLN DCs to promote $\mathrm{T}_{\mathrm{H}}$ 17-cell differentiation. The culture of T cells with MLN DCs, TGF $\beta$, IL-6 and a retinoic-acid receptor (RAR) antagonist reversed the reduced ability of MLN DCs to promote $T_{H} 17$-cell differentiation, resulting in the differ- entiation of similar numbers of $\mathrm{T}_{\mathrm{H}} 17$ cells as with splenic DCs. By contrast, addition of all-trans retinoic acid to cultures with splenic DCs inhibited their induction of $\mathrm{T}_{\mathrm{H}} 17$ cells. Retinoic acid also inhibited the expression of the $\mathrm{T}_{\mathrm{H}} 17$-cell-associated transcription factor retinoic-acid-receptor-related orphan receptor- $\gamma \mathrm{t}(\mathrm{ROR} \gamma \mathrm{t})$ in $\mathrm{T}_{\mathrm{H}} 17$ cell-inducing conditions. So, retinoic acid inhibits TGF $\beta$ - and IL-6-driven $\mathrm{T}_{\mathrm{H}} 17$-cell differentiation. The suppressive effect of retinoic acid on $\mathrm{T}_{\mathrm{H}} 17$ cells was also confirmed in vivo.

Next, the authors asked if MLN DCs preferentially promoted the differentiation of TGF $\beta$-dependent regulatory $\mathrm{T}$ cells, as determined by their expression of forkhead box P3 (FOXP3). MLN DCs induced more FOXP $^{+} \mathrm{T}$ cells in the presence of TGF $\beta$ compared with splenic DCs. The addition of a RAR antagonist reduced this TGF $\beta$-dependent FOXP3 induction, whereas addition of retinoic acid enhanced it. Regulatory $\mathrm{T}$ cells generated in the presence of both TGF $\beta$ and retinoic acid were functional in vivo and protected mice from colitis, whereas TGF $\beta$-induced regulatory $T$ cells were only partially protective.

Under conditions that promote $\mathrm{T}_{\mathrm{H}} 17$-cell differentiation (TGF $\beta$ and
IL-6), retinoic acid induced the differentiation of regulatory $\mathrm{T}$ cells, indicating that retinoic acid might override the promotion of TGF $\beta$-induced $\mathrm{T}_{\mathrm{H}} 17$-cell differentiation by IL-6.

So, the data show that retinoic acid regulates the reciprocal differentiation of TGF $\beta$-induced regulatory $T$ cells and $T_{H} 17$ cells. This study has important implications for the understanding of vitamin A deficiency and highlights the therapeutic potential of retinoic acid in diseases in which there is an imbalance in the numbers of TGF $\beta$-dependent $T_{H} 17$ cells and regulatory $\mathrm{T}$ cells.

More recently, three papers published in The Journal of Experimental Medicine (see Further Reading) show that the induction of regulatory $T$ cells by DCs in the gut depends on TGF $\beta$ and retinoic acid, highlighting a specific role for retinoic acid in the mucosal immune system.

Olive Leavy

ORIGINAL RESEARCH PAPER Mucida, D. et al. Reciprocal Th-17 and regulatory T cell differentiation mediated by retinoic acid. Science 14 June 2007 (doi:10.1126/science.1145697) FURTHER READING Sun, C.-M. et al. Small intestine lamina propria dendritic cells promote de novo generation of Foxp $3 \mathrm{~T}$ reg cells via retinoic acid.J. Exp. Med. 9 July 2007 (doi:10.1084/ jem.20070602) |Benson, M. J., Pino-Lagos, K., Rosemblatt, M. \& Noelle, R. J. All-trans retinoic acid mediates enhanced T reg cell growth, differentiation, and gut homing in the face of high levels of co-stimulation.J. Exp. Med. 9 July 2007 (doi:10.1084/jem.20070719)|Coombes, J. L. et al. A functionally specialized population of mucosal CD103' DCs induces Foxp $3^{+}$regulatory Tcells via a TGF- $\beta$ - and retinoic acid-dependent mechanism. J. Exp. Med. 9 July 2007 (doi:10.1084/jem.20070590) 